\title{
Q\&A
}

\section{The reformer}

Mostafa Moin is a paediatrician and medical researcher who has served as Iran's minister for higher education and for science. He was a reformist candidate in Iran's presidential election last year, which was won by religious conservative Mahmoud Ahmadinejad. Declan Butler asks Moin about the prospects for science in Iran.
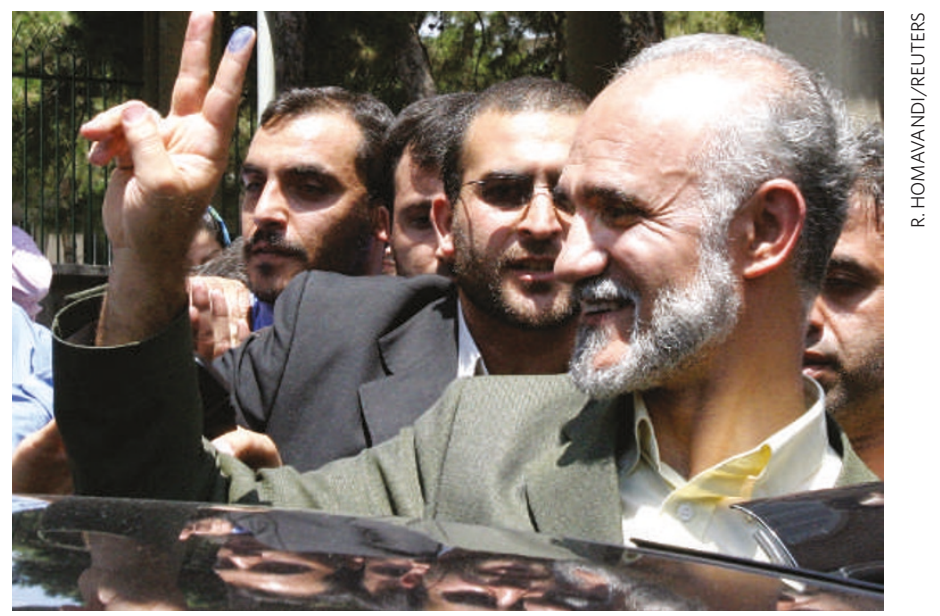

\section{How do you see the interplay between} science, religion and reform in Iran? Iranian society has long been deeply religious, even before the Islamic era began in 651 . But over the past 150 years, Iran has also pioneered struggles for freedom and opposition of dictatorship.

In the past few decades, reformers and religious neo-intellectuals with a common attachment to the principles of a civil and democratic society have cultivated democratic structures in Iranian society.

These will undoubtedly prepare the ground for greater scientific development and help a knowledge-based society to materialize. Islam itself is not anti-science, but I have always been concerned that superficial, narrowminded and non-democratic interpretations of Islam - and the political behaviour of certain traditional administrators - risk having a negative impact on both scientific development and social reforms in Iran.

What is your assessment of Mahmoud Ahmadinejad's track record on science, academic freedom and social reforms? The new government has overlooked the science and higher-education sectors in the 14 months it has been in power. It has also replaced almost all the university chancellors, and senior research and higher-education officials. When I was minister of science, research and technology, senior university officials were elected by the academic staff; the new government appoints them directly.

There is no doubt that this political control has resulted in purging, restrictions and criticism of independent forces. Renowned academics have been forced into retirement, and repression of politically active students and student organizations is escalating. International scientific exchange has not been immune from these narrow-minded approaches: students are no longer sent abroad and sabbaticals are restricted.

The government has cracked down on reformist newspapers, activists and political parties. The Shargh Daily, for example, one of the highest-circulation reformist newspapers, was shut down in September. I've also heard that admission of female students to universities is being restricted; I hope my information is incorrect.

\section{How optimistic are you that Iran can find a route to political reform?}

In the short term, it can't be predicted whether things will get better or worse. But I'm optimistic for the medium term. There is a global movement towards greater civil rights, and an expansion of democracy. It is this, and the growing awareness of the Iranian people of these issues, the vigilance of its youth and women, that will shape Iran's future.

\section{What are the biggest obstacles to improving Iran's international isolation?} International scientific cooperation with Iranian universities and scientists has greatly increased in the past few years. But it's not surprising that the nuclear crisis and the unscientific and unsustainable policies of the new government may have overshadowed this process. Current foreign policy is based on confrontation, and is shifting away from former president Mohammad Khatami's 'dialogue of civilizations.' This is the main obstacle at present.

\section{What should colleagues elsewhere think about Iran's nuclear programme?} I am sure that my learned academic colleagues abroad would not accept discrimination against Iran's legitimate right to the peaceful use of nuclear energy within the framework of global regulations. The problem is the accusations by the ruling neo-conservative radicals in the United States over programmes of weapons of mass destruction in Iran, while proposing double standards within the Middle East and the rest of the world.

The same accusations have been made before, but experts, scholars and international institutions proved them unfounded. If the United States were to implement unilateralist, violent and nonnegotiable policies against Iran, this would be a great catastrophe, increasing regional and global crises, expanding terrorism and consolidating dictatorships.

What were the major defining events in Iranian science over the past two decades? The expansion of higher education in the country, with university students increasing from 400 to more than 3,000 students per 100,000 people, between 1979 and 2000. The student-lecturer ratio has also improved from about 36:1 in 1989 to $18: 1$ in 2006 .

I regret that the structural reform in higher education in Iran has remained unfinished, and that the autonomy of universities and academic freedom were not institutionalized.

What are your own plans for the future? In the past two to three years I have founded two non-governmental organizations, the Association for Scientific Development of Iran and the Iranian Association for Ethics in Science and Technology. As president of the Immunology, Asthma and Allergy Institute at Tehran University of Medical Sciences, I'm active in teaching and research.

I have respected the commitment I made to the Iranian people during last year's election, with the creation of the Democracy and Human Rights Front. I want more than ever to strengthen civil and scientific institutions and structures, particularly for the young. 